\title{
A new DR7-DQ8 haplotype resulting from a recombination between the DQA1 and DQB1 loci in a leukemic patient of Caucasoid origin
}

Received: 3 March 2004 / Revised: 6 April 2004 / Published online: 23 June 2004

C) Springer-Verlag 2004

\begin{abstract}
Meiotic recombinations within the $H L A-D R / D Q$ subregion are seldomly observed. However the high number of unusual $D R B 1-D Q B 1$ allelic combinations underline the importance of crossover in shaping the class II haplotypic diversity. We present here the first report of a $D Q A 1-D Q B 1$ recombination event in a leukemic patient as detected by complete class II molecular typing of the family, including analysis of the DQCAR microsatellite. The recombination that occurred on the maternal chromosomes led to the unusual $D R 7-D Q 8$ haplotype characterized by the $D R B 1 * 0701$ $D R B 4^{*} 01030102 N-D Q A 1 * 0201-D Q B 1 * 0302$ alleles. Because the patient had no $H L A$-identical sibling donor, a search for an unrelated hematopoietic stem cell donor was initiated. Out of three potential donors, only one $H L A-A /$ $B /-C / D R B 1$-compatible but $D Q B 1$-mismatched donor could be identified.
\end{abstract}

Keywords Recombination - $D Q A 1-D Q B 1$ haplotype . $D Q C A R \cdot$ Unrelated HSCT

Recombination rates within the human MHC have been reported to range between $0.63 \mathrm{cM} / \mathrm{Mb}$ (Martin et al.1995) and $0.49 \mathrm{cM} / \mathrm{Mb}$ (Cullen et al. 2002). A high resolution map of recombination through the human MHC led to the identification of six segments, out of 30 segments subdividing the entire MHC, with levels of recombination 1.7- to 5.2-times higher than that expected, although none of the classical HLA loci were included in any of these

J.-M. Tiercy $(\bowtie) \cdot$ J. Villard

Transplantation Immunology Unit, National Reference Laboratory for Histocompatibility, University Hospital, 24 rue Micheli-du-Crest,

1211 Geneva 4, Switzerland

e-mail: jean-marie.tiercy@medecine.unige.ch

Tel.: +41-22-3729401

Fax: $+41-22-3729390$ segments. In the class II region, two hotspots were identified: from $D P B 1$ to $R I N G 3$, and from $D Q B 3$ to $D Q B 1 / D Q A 1$ (Cullen et al.2002).

Although crossovers between $H L A-A$ and $-B, H L A-B$ and $D R B 1$, or $D Q B 1$ and $D P B 1$ loci are not exceptional in the routine clinical laboratory, a meiotic recombination event between DRBI and DQA1 loci has only been described once in a family study with Grave's disease (Sullivan et al. 1997). On the other hand, unusual associations between $D R B 1$ and $D Q B 1$ alleles are well characterized (Klitz et al. 2003), and have been assumed to result from recombinations in ancestral haplotypes (Gregersen et al. 1988; Begovich et al. 1992; Carcassi et al. 1992).

We describe here a family with a meiotic recombination event that occurred on the maternal class II haplotypes between the DQA1 and $D Q B 1$ loci that are distant by $11.13 \mathrm{~kb}$ (http://www.ncbi.nlm.nih.gov/mapview/). HLA typing was requested for an acute myeloid leukemia patient and her family members in a search for a bone marrow donor. Based on the ABDR generic typing results, the segregation of the haplotypes in the family showed that none of the two siblings were $H L A$ genotypically identical with the patient (Fig. 1). In order to initiate an unrelated bone marrow donor search $H L A-C$ and $-D Q B 1$ typing was performed (Tiercy et al. 2002). The results showed that the patient had inherited a recombinant DRB1*0701$D Q B 1^{*} 0302$ haplotype (Fig. 2). High-resolution DNA typing for $D R B 1, D Q A 1, D Q B 1, D P B 1$, and of the $D Q C A R$ microsatellite (Lin et al. 1997) confirmed that recombination occurred between the $D Q A 1$ and $D Q B 1$ loci (Fig. 2). Both parents share the common $D R 7 / D Q 9 /$ DR53 null class II haplotype: DRB1*0701$D R B 4 * 01030102 N-D Q A 1 * 0201-D Q B 1 * 030302$ linked to the DQCAR 119 allele, as observed in several $D R 7 / D Q 9$ cell lines (Lin et al. 1997). The second $D R 7 / D Q 2$ paternal haplotype presents the common association with the $D Q C A R \quad 113$ allele. Microsatellite analysis of the $D Q C A R$ locus was informative for mapping the crossover 


\begin{tabular}{|c|c|c|}
\hline \multirow[t]{2}{*}{ father } & A1-B51-DRB1*07 & $\mathrm{a}$ \\
\hline & A2-B57-DRB1*07 & $b$ \\
\hline \multirow[t]{2}{*}{ mother } & A1-B7-DRB1*04 & $\mathrm{c}$ \\
\hline & A2-B7-DRB1*07 & d \\
\hline \multirow[t]{2}{*}{ patient } & A1-B51-DRB1*07 & a \\
\hline & A2-B7-DRB1*07 & d \\
\hline \multirow[t]{2}{*}{ sibling 1} & A2-B57-DRB1*07 & $b$ \\
\hline & A1-B7-DRB1*04 & c \\
\hline \multirow[t]{2}{*}{ sibling 2} & A2-B57-DRB1*07 & $b$ \\
\hline & A1-B7-DRB1*04 & $\mathrm{c}$ \\
\hline
\end{tabular}

Fig. 1 Segregation of the $H L A-A B D R$ haplotypes in the proband family. HLA-AB antigens were determined by serology (Biotest $\mathrm{AB} 120$, Pelfreez 144 trays), and $D R B 1$ generic typing was performed by reverse PCR-SSOP hybridization (bioMérieux)

in the DQA1-DQCAR 10.2-kb genomic segment (Fig. 2), a hotspot that has been described previously (Lin et al. 1997).

The $D R B 1 * 0701-D Q A 1 * 0201-D Q B 1 * 0302$ haplotype identified in this patient represents a new $D R 7-D Q 8$ haplotype in addition to the four $D R-D Q$ haplotypes found in a large sample of donors from different ethnic groups; i.e., $D R B 1 * 0701-D Q A 1 * 0201-D Q B 1 * 0202, D R B 1 * 0701$ $D Q A 1 * 0201-D Q B 1 * 0301, \quad D R B 1 * 0701-D Q A 1 * 0302-$ $D Q B 1 * 0301$, and $D R B 1 * 0701-D Q A 1 * 0201-D Q B 1 * 0303$
(Lin et al. 1997; Klitz et al. 2003). The $D R 7-D Q 7$ association $\left(D R B 1^{*} 0701-D Q B 1 * 0301\right)$ has been reported once in another study, but DQA1 and DRB4 alleles were not determined (Knipper et al. 2000).

While searching an unrelated HSC donor through Bone Marrow Donor Worldwide, only three potential donors with the phenotype A1/2; B7/51; DR7/7 could be tested, two of these being in fact $D R B 1$-mismatched (because of a $D R B 1 * 1303$ and a $D R B 1 * 1401$ allele, respectively, not identified by the recruiting center). Based on the definition of the new $D R 7-D Q 8$ haplotype in the patient, it could be predicted that $D Q B 1$ matching would be extremely unlikely, and that the transplant center should consider a $D Q$-mismatch. The third donor, who was eventually selected, was compatible for all class I and II loci, with the exception of a $D Q B 1$ mismatch. This clinical case underlines the importance of $D Q$ typing before initiating unrelated HSC donor searches. Although the clinical relevance of $D Q$ disparities still remains to be demonstrated, $D Q$ typing may contribute to discriminate between equally $H L A-A /-B /-C / D R B 1$-matched donors that would also be equivalent for non-HLA criteria.

Acknowledgements The authors are grateful to F. Bettens and to the technicians of the LNRH for performing HLA serology, highresolution DNA typing and microsatellite analyses. This study was supported by a grant from the Swiss National Science Foundation (No 3100-068260). We thank Genovision for the generous gift of DQA1 PCR-SSP reagents.

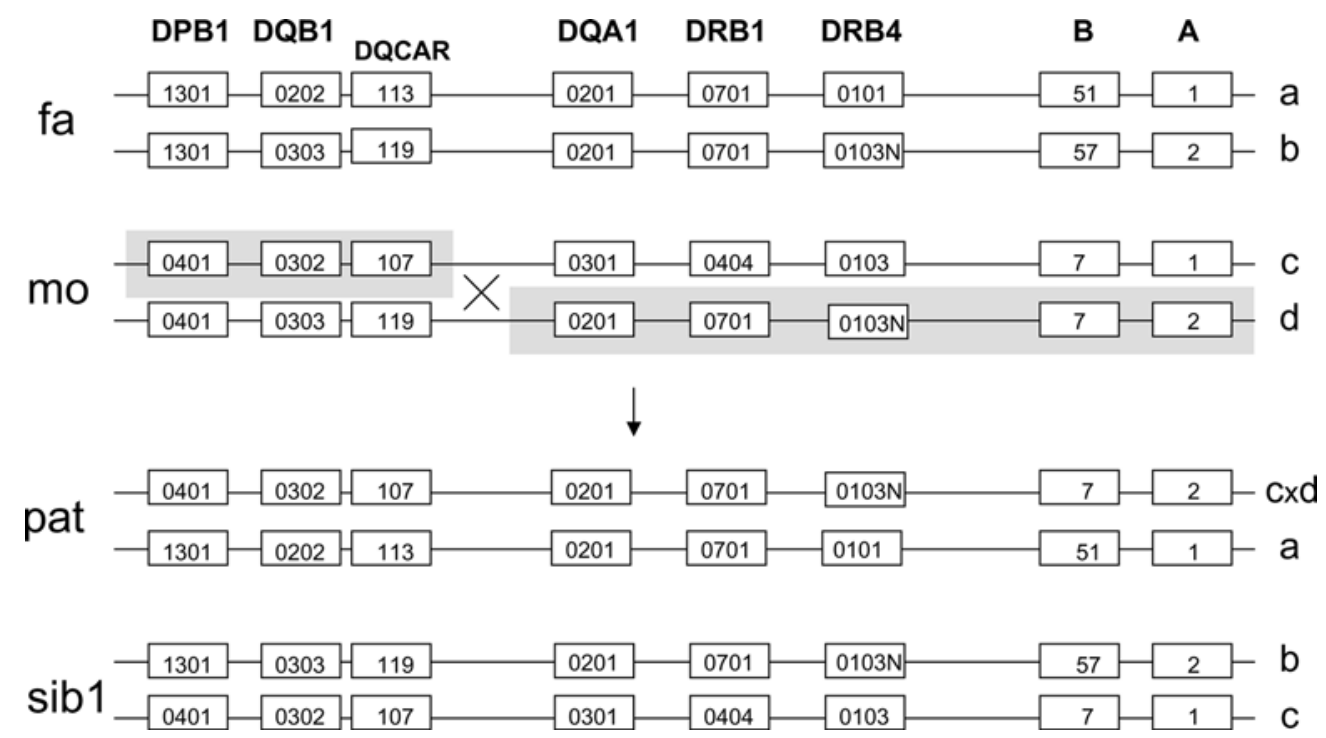

Fig. $2 H L A-D Q A 1 / D Q B 1$ recombination between the maternal haplotypes demonstrated by high-resolution DNA typing for class II loci in the proband family. Only sibling 1 is shown here. Allele-level typing for the $D R B 1, D R B 4, D Q A 1, D Q B 1$, and $D P B 1$ loci was performed by PCR-SSP, as described by the supplier (Genovision, Milan Analytica, La Roche, Switzerland). DRB4*0103N corresponds to the $D R B 4^{*} 01030102 N$ allele. DQCAR microsatellite polymorphism was analyzed as described by Lin et al. (1997), using an ABI 310 capillary sequencer. Alleles are indicated by the size (bp) of the PCR products, using as control cell lines YAR (111 bp), AMALA (117 bp), BM21 and JVM (121 bp). Shaded areas correspond to the MHC segments of the $c$ and $d$ haplotypes, respectively, that have undergone recombination ( $\mathrm{fa}$ father, mo mother, pat patient, sib1 sibling 1) 


\section{References}

Begovich AB, McClure GR, Suraj VC, Helmuth RC, Fildes N, Bugawan TL, Erlich HA, Klitz W (1992) Polymorphism, recombination, and linkage disequilibrium within the HLA class II region. J Immunol 148:249-258

Carcassi C, Giorda R, Trucco M, Contu L (1992) A novel HLA-DR4 haplotype generated by a rare recombinational event between $D R B 1$ and $D Q A 1$ loci. Immunogenetics 36:338-340

Cullen M, Perfetto SP, Klitz W, Nelson G, Carrington M (2002) High-resolution patterns of meiotic recombination across the human major histocompatibility complex. Am J Hum Genet 71:759-776

Gregersen PK, Kao H, Nunez-Roldan A, Hurley CK, Karr RW, Silver J (1988) Recombination sites in the HLA class II region are haplotype dependent. J Immunol 141:1365-1368

Klitz W, Maiers M, Spellman S, Baxter-Lowe LA, Schmeckpeper B, Williams TM, Fernandez-Vina M (2003) New HLA haplotype frequency reference standards: high-resolution and large sample typing of $H L A D R-D Q$ haplotypes in a sample of European Americans. Tissue Antigens 62:296-307
Knipper AJ, Hakenberg P, Enczmann J, Kuhrober A, Kiesel U, Kogler G, Wernet P (2000) HLA-DRB1, 3, 4, 5 and $-D Q B 1$ allele frequencies and $H L A-D R / D Q$ linkage disequilibrium of 231 German Caucasoid patients and their corresponding 821 potential unrelated stem cell transplants. Hum Immunol 61:605-614

Lin L, Jin L, Kimura A, Carrington M, Mignot E (1997) $D Q$ microsatellite association studies in three ethnic groups. Tissue Antigens 50:507-520

Martin M, Mann D, Carrington M (1995) Recombination rates across the HLA complex: use of microsatellites as a rapid screen for recombinant chromosomes. Hum Mol Genet 4:423-428 (erratum: Hum Mol Genet 4:2423)

Sullivan KA, Wolfe MA, Lopez M, Jaspan JB, Bryer-Ash M (1997) First report of recombination between the HLA-DR and HLA$D Q$ loci within a family. Hum Immunol 57:37-43

Tiercy JM, Villard J, Roosnek E (2002) Selection of unrelated bone marrow donors by serology, molecular typing and cellular assays. Transplant Immunol 10:215-221 